\title{
Flora da Bahia: Chloranthaceae
}

\section{Lara Pugliesi de Matos $^{1 *}$, Ana Maria Giulietti ${ }^{1,2, a} \&$ Reyjane Patrícia de Oliveira ${ }^{1, b}$}

${ }^{1}$ Programa de Pós-Graduação em Botânica, Departamento de Ciências Biológicas, Universidade Estadual de Feira de Santana, Feira de Santana, Bahia, Brasil.

${ }^{2}$ Instituto Tecnológico Vale, Belém, Pará, Brasil.

Resumo - É apresentado aqui o tratamento taxonômico de Chloranthaceae para o estado da Bahia, Brasil. Hedyosmum brasiliense é a única espécie da família na Bahia. São apresentados descrições, ilustrações, comentários e um mapa de distribuição da espécie no estado.

Palavras-chave adicionais: Chloranthales, Hedyosmum, Nordeste, plantas dioicas, taxonomia.

Abstract (Flora of Bahia: Chloranthaceae) - The taxonomic treatment of Chloranthaceae from the Bahia state, Brazil, is presented here. Hedyosmum brasiliense is the only species of the family in Bahia. Descriptions, illustrations, notes and a distribution map of the species in the state are presented.

Additional key words: Chloranthales, dioecious plants, Hedyosmum, Northeast Brazil, taxonomy.

\section{CHLORANTHACEAE}

Árvores, arbustos ou ervas, aromáticos. Folhas simples, decussadas, peninérveas, geralmente glabras, margem crenada, denteada ou serreada; bainhas do par oposto das folhas expandidas e unidas, formando uma estrutura similar a ócrea; estípulas peciolares e interpeciolares, estas últimas adnatas à bainha. Inflorescências axilares ou terminais, sem brácteas ou com 1-3 brácteas subjacentes, espiciformes, racemosas ou paniculadas. Flores uni ou bissexuadas; as estaminadas aclamídeas, com 1-3 estames, anteras 2- ou 4-esporangiadas, rimosas; as pistiladas epíginas ou hemiepíginas, mono ou aclamídeas, unicarpelares, uniloculares, óvulo pêndulo. Frutos drupas ou aquênios; semente oleosa, endosperma amiláceo.

Chloranthaceae pertence à ordem Chloranthales (APG IV 2016) e inclui cerca de 75 espécies e quatro gêneros: Chloranthus Sw. (10 espécies), Sarcandra Gardner (2) e Ascarina J.R.Forster \& G.Forster (1020), confinadas à região tropical do Velho Mundo, e Hedyosmum Sw., essencialmente neotropical, mas com uma espécie no sudeste asiático (Todzia 1988, 1993; Antonelli \& Sanmartín 2011). Flores unissexuadas são compartilhadas por Hedyosmum e Ascarina, enquanto Chloranthus e Sarcandra possuem flores bissexuadas, e os quatro gêneros diferem entre si pelo tipo de grão de pólen e o número cromossômico (Todzia 1988). A família está entre as linhagens mais antigas de angiospermas, o que é sustentado por diferentes fontes de evidência: 1- estudos filogenéticos com dados moleculares (Qiu et al. 2000; Savolainen et al. 2000; Soltis et al. 2000; Moore et al. 2007; Morton 2011), 2riqueza de registros fósseis para o Cretáceo, que inclui

\footnotetext{
*Autora para correspondência larapugli@gmail.com;

aanagiulietti@hotmail.com; brpatricia@uefs.br

Editor responsável: Alessandro Rapini

Submetido: 31 maio 2016; aceito: 5 out. 2016
}

Publicação eletrônica: 18 out. 2016; versão final: 25 out. 2016 flores, grãos de pólen (Clavatipollenites R.A.Couper e Asteropollis R.W.Hedl. \& G.Norris) e cutículas foliares (Friis et al. 1986; Todzia 1993; Eklund et al. 2004; Friis et al. 2015); e 3- estrutura floral simples, que atrai polinizadores pela cor e aroma (Endress 1987; Balthazar \& Endress 1999; Endress 2001; Doyle et al. 2003; Eklund et al. 2004; Endress \& Doyle 2009). No Brasil, a família está representada apenas pelo gênero Hedyosmum (BFG 2015; Leitman 2015).

\section{Hedyosmum Sw.}

Árvores ou arbustos, raramente ervas, monoicas ou dioicas. Folhas carnosas a cartáceas, margem denteada, serreada ou crenada; pecíolo com bainha frouxa e estípulas peciolares e interpeciolares. Inflorescências estaminadas compostas de 1 a várias espigas, cada espiga com 18-300 flores; as pistiladas em tirsos, racemos ou panículas de cimeiras 2-15floras ou mais raramente de flores solitárias, brácteas florais cuculadas, envolvendo ou não a flor. Flores estaminadas reduzidas a 1 estame séssil, conectivo estendido em um curto apêndice, anteras 4esporangiadas; as pistiladas com perianto caliciforme, 3-lobado, epíginas, estigma séssil. Frutos drupas globosas, ovoides ou trígonas, exocarpo carnoso; semente elipsoide ou trígona.

Hedyosmum reúne cerca de 45 espécies, distribuídas desde o México (Vera Cruz), Caribe e América Central, até a América do Sul; apenas $H$. orientale Merr. \& Chun ocorre no sudeste da Ásia (Todzia 1988, 1993). Provavelmente, a linhagem de Hedyosmum divergiu dos outros três gêneros de Chloranthaceae durante o Cretáceo Inferior ( 100 milhões de anos), na Laurásia, mas se dispersou para as Américas e iniciou sua diversificação na região neotropical há cerca de 40 milhões de anos, possivelmente associada ao soerguimento dos Andes (Antonelli \& Sanmartín 2011). No Brasil, são registradas três espécies: $H$. brasiliense Mart. ex Miq., que ocorre em todas as Regiões, além de H. neblinae 
Todzia e H. racemosum (Ruiz \& Pav.) G.Don, referidas apenas para a Serra da Neblina, no extremo norte do estado do Amazonas (Todzia 1988; Leitman 2015). Na Bahia, é registrada apenas $H$. brasiliense.

Hedyosmum brasiliense Mart. ex Miq. in Martius, Fl. Bras. 4(1): 3. 1852.

Figuras 1 e 2 .

Nomes populares: chá-de-soldado e cidreira.

Árvores ou arbustos dioicos, 2-5 $\mathrm{m}$ alt., ramos nodosos. Folhas com lâmina 4,6-16,5 × 1,3-5,7 cm, cartácea ou subcarnosa, elíptica ou oblanceolada, ápice agudo, margem crenada ou serreada, base cuneada, face adaxial glabra, in vivo verde-brilhosa, face abaxial com tricomas esparsos na nervura central, in vivo verde-clara; pecíolo verde ou vináceo, 0,3-1,4 cm compr.; bainha peciolar com tricomas alinhados verticalmente ou glabra, cada margem distal com duas projeções fimbriadas. Inflorescências estaminadas axilares ou terminais verdes a verde-amareladas, pedúnculo $0,5-2 \mathrm{~cm}$ compr., brácteas do nó basal 8-15 mm compr., raque 1,5-2 cm compr.; espigas $3-8,0,5-1,3 \times 0,4-0,6 \mathrm{~cm}$, subtendidas por brácteas estreitamente triangulares, 2-4 mm compr.; flores com estame ca. $1 \mathrm{~mm}$ compr. Inflorescências pistiladas axilares ou terminais, verdes, tirsos, brácteas 3-5 mm compr.; cimeiras 2-6, 2-4(5)-floras, bráctea floral verde, carnosa, 3,5-6 mm compr., cobrindo mais da metade da flor; flores com lobos do perianto levemente triangulares a trilobados, $0,2-1 \times 0,4-0,5 \mathrm{~mm}$, ovário 2-3 $\times 1,5-2,8 \mathrm{~mm}$, estigma 1-3 $\times 0,5-2 \mathrm{~mm}$, Drupas trígonas, 3-4,5 × 2-2,5 mm; semente trígona, $2,5-3 \times$ 1,8-2 $\mathrm{mm}$.

Hedyosmum brasiliense foi citada por Todzia (1988) apenas para o Brasil e o Paraguai, mas já há registros também para a Bolívia e a Colômbia (TROPICOS). No Brasil, está presente em todas as Regiões, nos domínios da Amazônia, Cerrado e Mata Atlântica (Leitman 2015). Ocorre preferencialmente em florestas montanas, e em áreas altas de cerrados e campos rupestres, especialmente nas florestas ciliares (Pirani 1987; Rossi 1996; Leitman 2015). D7, E3, E6, F3, F6, G7, G8, H8: na Chapada Diamantina, ocorre em florestas montanas associadas aos campos rupestres, em altitudes entre 1.400 a $1.800 \mathrm{~m}$, geralmente associada a Drimys brasiliensis Miers (Winteraceae) e Weinmannia pauliniifolia Pohl. (Cunnoniaceae) (Nascimento et al. 2010), ou em florestas ciliares em menores altitudes. Ocorre também em remanescentes de floresta atlântica montana do sul da Bahia, entre 860 e 1.000 m s.n.m. (Amorim et al. 2009; Coelho \& Amorim 2014). Pode ser encontrada mais raramente em florestas ciliares no Cerrado do oeste baiano.

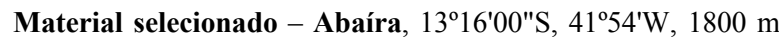
s.n.m., 16 nov. 1992 (fl. 9 , fr.), W. Ganev 1469 (HUEFS); Água Quente, 1700 m s.n.m., 6 out. 1998 (fl. §ึ), F.H.F. Nascimento 52

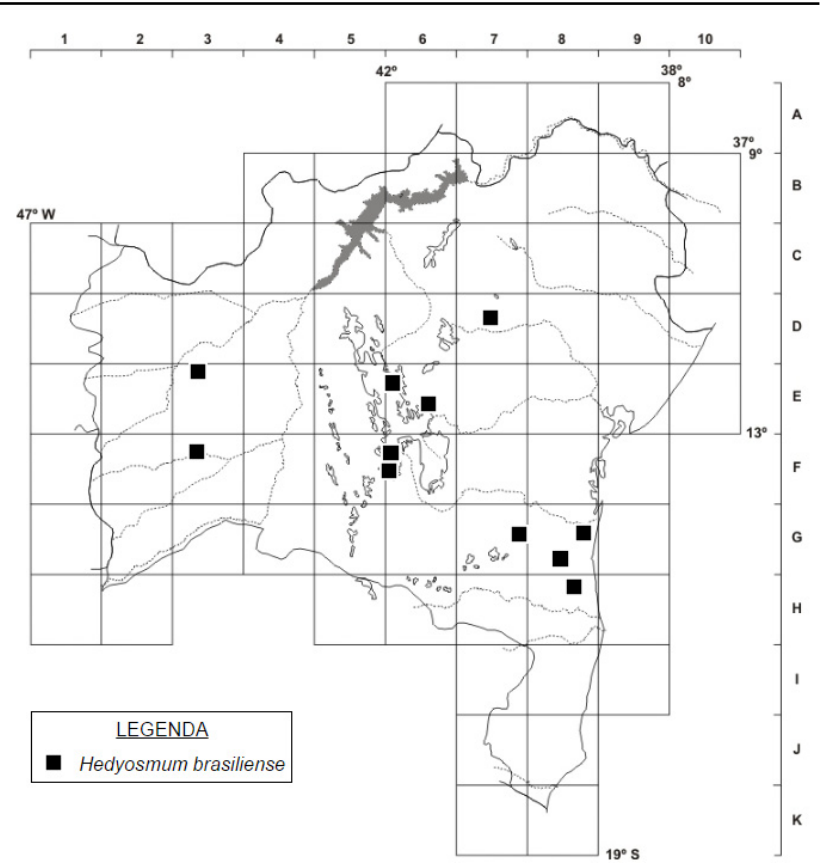

Figura 1. Mapa de distribuição de Hedyosmum brasiliense no estado da Bahia.

(HUEFS); Angical, nascente da fonte d'água Buritizal, 1206'30"S, 4438'34"W, 26 jan. 2010 (fr.), K. Yoshida-Arms et al. 90 (HUEFS); Arataca, Serra do Peito de Moça, 15²10'25"S, 39²0'30"W, $1000 \mathrm{~m}$ s.n.m, 23 set. 2007 (fl.ㅇ, fr.), F.M. Ferreira et al. 1436 (CEPEC); Barro Preto, Serra da Pedra Lascada, 14²46'13"S, 39³2'10"W, 860 m s.n.m., 13 mar. 2007 (fr.), M.M. Lopes et al. 1162 (CEPEC); Lençóis, Serra Larga, 12³3'47"S, 41²3'24"W, 1400 m s.n.m., 19 dez. 1984 (ふ̋), J.R. Pirani et al. 7180 (HUEFS); Rio de Contas,

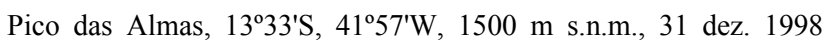
(fl.ㅇ, fr.), R.M. Harley et al. 53403 (HUEFS); 13³0'58,5”S, 41'56'59,5'W, 1520 m s.n.m., 18 out. 2012 (fl. ㅇ, bot), L.P. Matos et al. 44 (HUEFS); Rio do Pires, Campo do Cigano, 13¹5'43"S, 41 $55^{\prime} 29^{\prime \prime W}$ 1650-1750 m s.n.m., 5 dez. 2000 (fr.), F.H.F. Nascimento 405 (HUEFS).

Hedyosmum brasiliense apresenta grande variação morfológica ao longo de sua distribuição, especialmente em relação ao comprimento e forma dos dentes da margem das folhas, comprimento do pecíolo e forma das bainhas (Todzia 1988). Seu hábito assemelha-se ao de $H$. racemosum, que ocorre nas florestas andinas, entre 1.400 e 2.500 m s.n.m. (TROPICOS). Morfologicamente essas espécies se diferenciam porque $H$. racemosum apresenta folhas com margens denteadas (vs. crenadas a serreadas em $H$. brasiliense), apêndice estipular pouco ou não fimbriado (vs. fortemente fimbriado), inflorescências estaminadas mais longas (raque $4-8,8 \mathrm{~cm}$ vs. $1,5-2 \mathrm{~cm}$ ), bráctea das espigas cimbiforme (vs. estreitamente triangular), e cimeiras das inflorescências pistiladas podendo apresentar mais flores $[2-7$ vs. 2-4(5)]. Embora proximamente relacionadas e incluídas em Hedyosmum subg. Tafalla Solms, dados moleculares dos genomas plastidial e nuclear indicam que $H$. brasiliense e $H$. racemosum devem ser tratadas como espécies distintas (Antonelii \& Sanmartín 2011). 


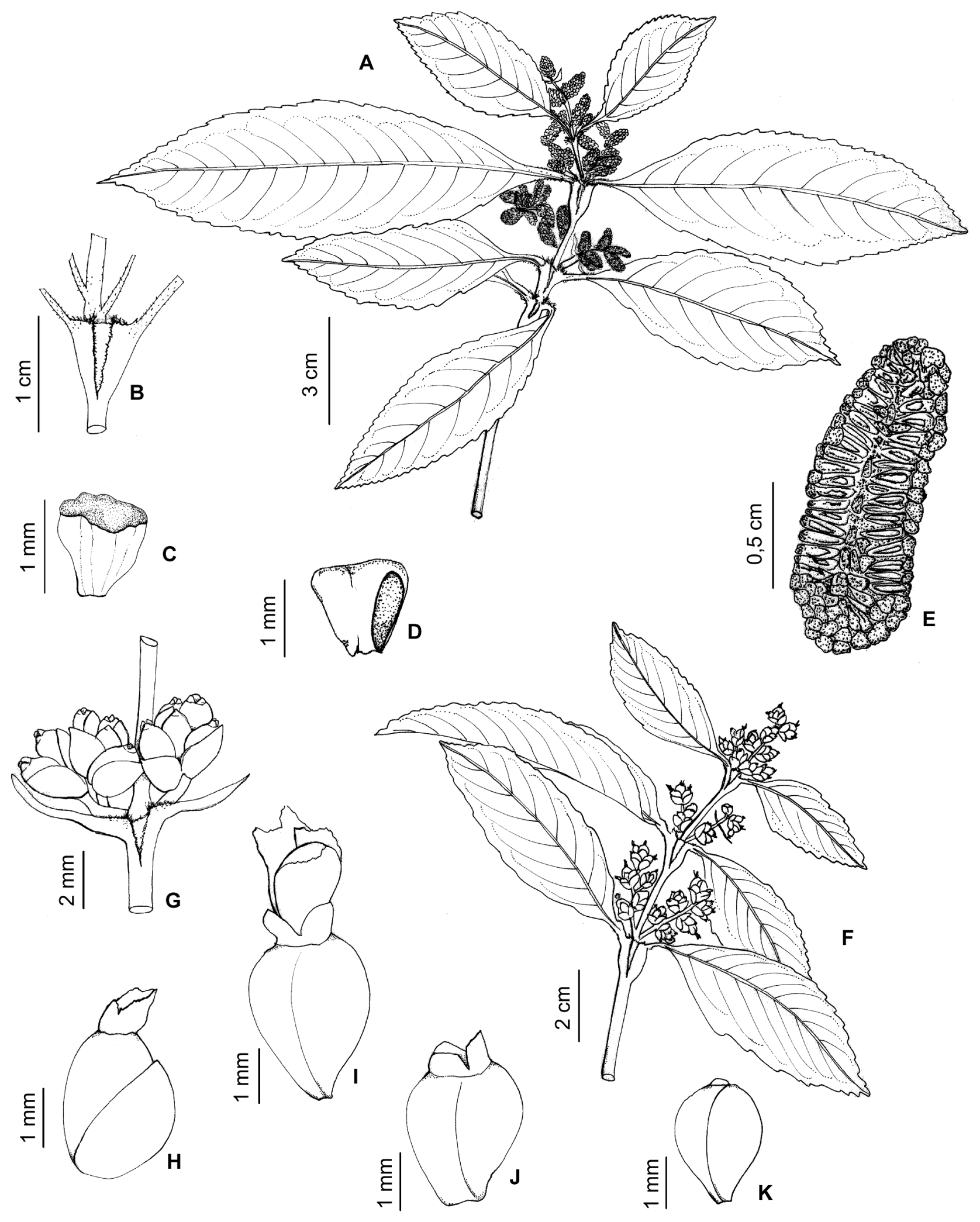

Figura 2. Hedyosmum brasiliense: A- ramo com inflorescências estaminadas; B- nó de um ramo, mostrando a bainha peciolar fundida similar a ócrea; C- estame fechado; D- estame aberto; E- espiga estaminada; F- ramo com inflorescências pistiladas; G- cimeiras em frutos; H- flor pistilada em botão; I- flor pistilada madura; J- fruto; K- semente (A, C-E- Nascimento 52; B- Harley 53403; F, J, K- Matos 44; G- Nascimento 405; H- Ferreira 1640; I- Yoshida-Arms 90). 


\section{AGRADECIMENTOS}

Aos curadores dos herbários, pelo acesso às coleções. À Pétala Gomes Ribeiro, pela arte final da ilustração em nanquim. À Fapesb e ao $\mathrm{CNPq}$, pelo auxílio financeiro aos Projetos Flora da Bahia e PPBIO Semiárido (processos FAPESB APR 162/2007 e CNPq 562278/2010-9, 483909/2012-2 e 457427/2012-4). Ao $\mathrm{CNPq}$, pelas bolsas de produtividade em pesquisa concedidas a Ana Maria Giulietti (PQ Senior) e Reyjane Patrícia de Oliveira (PQ1D), e de mestrado à Lara Pugliesi de Matos.

\section{REFERÊNCIAS}

Amorim, A.M.; Jardim, J.G.; Lopes, M.M.M.; Fiaschi, P.; Borges, R.A.X.; Perdiz, R.O. \& Thomas, W.W. 2009 Angiospermas em remanescentes de floresta montana no sul da Bahia, Brasil. Biota Neotropica 9(3): 313-348.

Antonelli, A. \& Sanmartín, I. 2011. Mass extinction, gradual cooling, or rapid radiation? Reconstructing the spatiotemporal evolution of the ancient angiosperm genus Hedyosmum (Chloranthaceae) using empirical and simulated approaches. Systematic Biology 60(5): 596-615.

APG IV 2016. An update of the Angiosperm Phylogeny Group classification for the orders and families of flowering plants: APG IV. Botanical Journal of the Linnean Society 181: 1-20.

Balthazar, M. \& Endress, P.K. 1999. Floral bract function, flowering process and breeding systems of Sarcandra and Chloranthus (Chloranthaceae). Plant Systematics and Evolution 195: 177-185.

BFG [The Brazil Flora Group] 2015. Growing knowledge: an overview of Seed Plant diversity in Brazil. Rodriguésia 66: 1085-1113.

Coelho, M.M. \& Amorim, A.M. 2014. Floristic composition of the montane forest in the Almadina-Barro Preto axis, southern Bahia, Brazil. Biota Neotropica 14(1): 1-41.

Doyle, J.A.; Eklund, H. \& Heredeen, P.S. 2003. Floral evolution in Chloranthaceae: implications of a morphological phylogenetic analysis. International Journal of Plant Sciences 164: 365-382.

Eklund, H.; Doyle, J.A. \& Heredeen, P.S. 2004. Morphological phylogenetic analysis of living and fossil Chloranthaceae. International Journal of Plant Sciences 165(1): 107-151.

Endress, P. 1987. The early evolution of the angiosperm flower. Trends in Ecology \& Evolution 2(10): 300-304.

Endress, P. 2001. The flowers in extant basal angiosperms and inferences on ancestral flowers. International Journal of Plant Sciences 162(5): 1111-1140.

Endress. P. \& Doyle, J.A. 2009. Reconstructing the ancestral angiosperm flower and its initial specializations. American Journal of Botany 96(1): 22-66.
Friis, E.M.; Crane, P.R. \& Pedersen, K.R. 1986. Flora evidence for Cretaceous chloranthoid angiosperms. Nature 320: 163-164.

Friis, E.M.; Grimm, G.W.; Mendes, M.M. \& Pedersen, K.R. 2015. Canrightiopsis, a new Early Cretaceous fossil with Clavatipollenites-type pollen bridge the gap between extinct Canrightia and extant Chloranthaceae. Grana 54(3): 184-212.

Leitman, P. 2015. Chloranthaceae. In: Lista de Espécies da Flora do Brasil. Jardim Botânico do Rio de Janeiro. Disponível em http://floradobrasil.jbrj.gov.br/jabot/floradobrasil/FB116824; acesso em 18 ago. 2016.

Moore, M.J.; Bell, C.D.; Soltis, P.S \& Soltis, D.E. 2007. Using plastid genome-scale data to resolve enigmatic relationships among basal angiosperms. Proceedings of the National Academy of Sciences of the United States of America 104(49): 19363-19368.

Morton, C.M. 2011. Newly sequenced nuclear gene $(X d h)$ for inferring angiosperm phylogeny. Annals of the Missouri Botanical Garden 98(1): 63-89.

Nascimento, F.H.F.; Giulietti, A.M. \& Queiroz, L.P. 2010. Diversidade arbórea das florestas alto montanas no sul da Chapada Diamantina, Bahia, Brasil. Acta Botanica Brasilica 24(3): 674-685.

Pirani, J.R. 1987. Flora da Serra do Cipó, Minas Gerais: Chloranthaceae. Boletim de Botânica da Universidade de São Paulo 9: 153-155.

Qiu, Y.; Lee, J.; Bernasconi-Quadroni, F.; Soltis, D.E.; Soltis, P.S.; Zanis, M.; Zimmer, E.A.; Chen, Z.; Savolainen, V. \& Chase, M.W. 2000. Phylogeny of basal angiosperms: analyses of five genes from three genomes. International Journal of Plant Sciences 161(6): S3-S27.

Rossi, L. 1996. Chloranthaceae. In: M.G.L. Wanderley, G.J. Shepherd \& A.M. Giulietti (eds), Flora Fanerogâmica da Ilha do Cardoso. Vol. 2. Instituto de Botânica, São Paulo, p. 83-84.

Savolainen, V.; Chase, M.W.; Hoot, S.B.; Morton, C.M.; Soltis, D.E.; Bayer, C.; Fay, M.F.; de Bruijn, A.Y.; Sullivan, S. \& Qiu, Y.L. 2000. Phylogenetics of flowering plants based on combined analysis of plastid $a t p B$ and $r b c L$ gene sequences. Systematic Biology 49: 306-362.

Soltis, D.E.; Soltis, P.S.; Chase, M.W.; Mort, M.E.; Albach, D.C.; Zanis, M.; Savolainen, V.; Hahn, W.H.; Hoot, S.B.; Fay, M.F.; Axtell, M.; Swensen, S.M.; Prince, L.M.; Kress, W.J.; Kevin, C.; Nixon, K.C. \& Farris, J.S. 2000. Angiosperm phylogeny inferred from 18S rDNA, $r b c L$, and $a t p B$ sequences. Botanical Journal of the Linnean Society 133: 381-461.

Todzia, C.A. 1988. Chloranthaceae. Flora Neotropica Monograph. Vol. 48. The New York Botanical Garden, New York.

Todzia, C.A. 1993. Chloranthaceae. In: K. Kubitzki, J.G. Rohwer \& V. Bittrich (eds). The Families and Genera of Vascular Plants. Flowering plants. Dicotyledons - magnoliid, hammamelid and caryophyllid families. Vol. 2. Springer-Verlag, Berlin, p. 281-287.

TROPICOS Missuri Botanical Garden. Disponível em http://www.tropicos.org/Name/7300006?tab=specimens; acesso em 8 set. 2016.

\section{LISTA DE EXSICATAS}

Amorim, A.M. 3651, 4791, 5336; Aona, L.Y.S. 1610, 1861; Azevedo, M.L.M. 295; Cordeiro, I. 5710; Costa-Lima, J.L. 827; Ferreira, F.M. 1436, 1640; Ferreira, J.L. 346; Ganev, W. 1469; Giulietti, A.M. 1605; Harley, R.M. 19629, 21878, 24586, 25923, 28319, 53403; 
Jardim, J.G. 4894; Lopes, M.M.M. 545, 1162; Matos, L.P. 44; Melo, E. 1684; Nascimento, F.H.F. 52, 231, 405; Nogueira, T.F. 1; Pirani, J.R. 7180; Santos, J.S. 143; Yoshida-Arms, K. 90. 